\title{
Voice analysis after cancer treatment with organ preservation
}

Renata JDS Campos ${ }^{1 * \dagger}$, Cristina TV Maciel ${ }^{2+}$, Marcelle G Cesca $^{3+}$ and Isabel CG Leite ${ }^{4+}$

\begin{abstract}
Background: This cross-sectional study objects to measure, subjectively and objectively, the voice and life quality of patients with oral cavity, pharyngeal and laryngeal cancer, after organ-preservation treatment.

Methods: 25 cases diagnosed and treated at a high complexity oncology center in southeastern Brazil. All had oral cavity, pharyngeal or laryngeal cancer, with a therapeutic proposal of radiotherapy alone or simultaneous radiochemotherapy. Acoustic voice analysis and the Voice Handicap Index protocol were used to measure voice quality. The data were analyzed through the $\chi 2$, Student's $t$ and Kruskal Wallis tests. Significance level was 5\%.

Results: After treatment, $40 \%$ complained of hoarseness, $56 \%$ complained of throat clearing, and no patient reported aphonia. On the voice quality auditory scale, $36 \%$ had moderate dysphonia. Acoustic voice analysis ranged from 184 to $221 \mathrm{~Hz}$ in females, and from 92 to $241 \mathrm{~Hz}$ in males. As for quality of life, most patients had mild physical, functional and emotional handicaps.

Conclusions: Chemio-radiation organ preservation protocols in the patients studied may leave the organ but with reduced function which brings communication sequelae. In such cases, voice assessment and quality of life protocols, as well as speech therapy rehabilitation, are important tools to preserve function, measure and treat alterations, and reintegrate patients into the community.
\end{abstract}

\section{Background}

Because several sequelae of oral communication may occur after treatment of head and neck cancer, research in this area is important to better describe the symptoms and adequately control the treated patients [1]. Costa Bandeira et al. [2], studying the quality of life and communication, voice and swallowing alterations of radiotherapy-treated tongue cancer patients, found voice and swallowing alterations and low quality of life scores after 1 year, stating the important role played by the speech therapist in the radiotherapy team.

This study aimed to analyze the voice pattern, through subjective and objective measurements, and the quality of life of head and neck cancer patients submitted to an organ-preservation protocol. The Voice Handicap Index (VHI) was used to measure voice quality [3].

\footnotetext{
* Correspondence: renatajdaniel@hotmail.com

+ Contributed equally

'Instituto Oncológico of Juiz de Fora; Voice specialist; Brazilian Health Master Program of the Federal University of Juiz de Fora, Minas Gerais, Brazil Full list of author information is available at the end of the article
}

\section{Methods}

\section{Study population}

The study was undertaken in the city of Juiz de Fora (Minas Gerais state), a reference for health care in southeastern Brazil, with an estimated population of 517,029 inhabitants [4].

It was a cross-sectional study, enrolling subjects diagnosed and treated at the Radiotherapy Division of a high complexity oncology center, during the period 2000-2006.

Subjects with stages T1, T2, T3 or T4 oral cavity, pharyngeal or laryngeal cancer, diagnosed and treated in the aforementioned institution, with a curative or palliative therapeutic proposal of radiotherapy alone or simultaneous radiochemotherapy, were included in the study. T4 patients were enrolled if they had declined surgery. Exclusion criteria were: death occurring previous to the study period; surgery (alone or in combination with other therapy) for head and neck cancer; story of previous neurological alteration (due to a possible interference with laryngeal physiology); physical, motor or emotional disorder precluding participation; and refusal to participate. Figure 1 shows a flowchart for patient selection.

\section{Biomed Central}




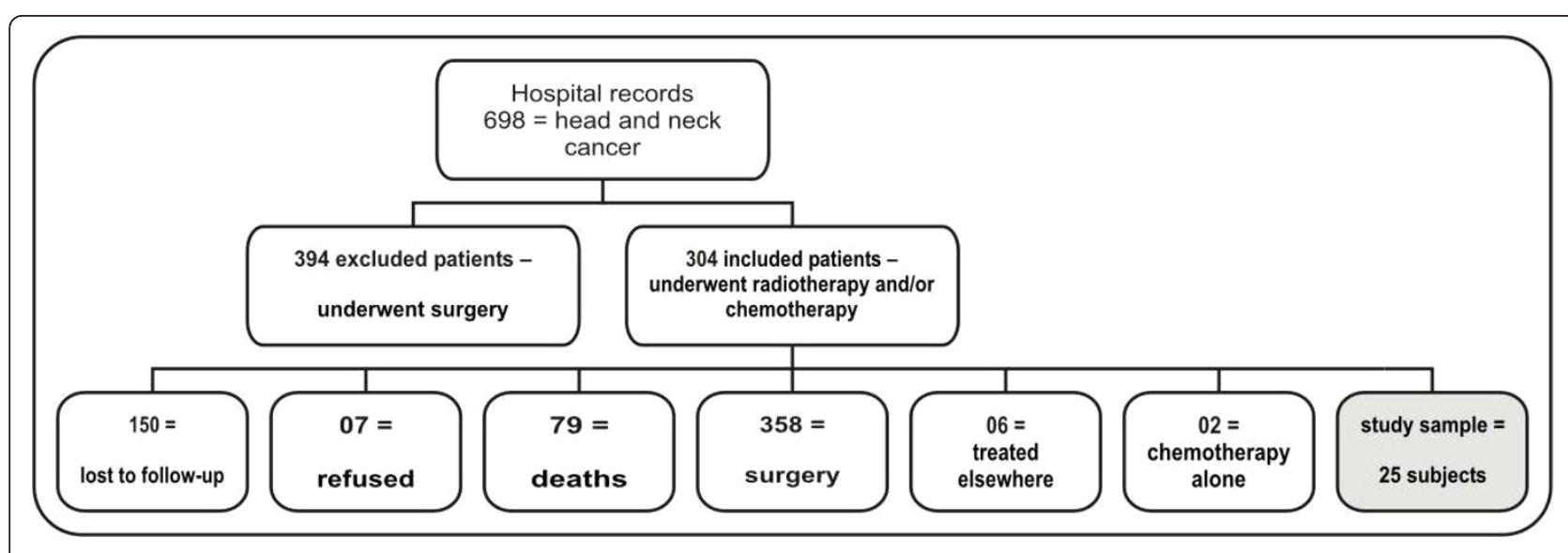

Figure 1 Study flowchart. Figure 1 shows a flowchart for patient selection. Its source is research data.

\section{Methods of study}

The 25 patients included were submitted to focused interview, voice assessment (acoustic and auditory-perceptual analyses) and assessment of the VHI. All stages of voice assessment and interview were performed in a room of the local speech therapy service, by one specifically trained examiner.

Voice analysis was performed according to the parameters and method proposed by Rehder and Behlau [5]. For auditory-perceptual analysis of oral communication, we recorded a voice sample consisting of sustained emissions of the/e/vowel at standard pitch and intensity, and performed other tests of voice content. The recordings were made with a professional microphone fitted to a portable microcomputer. The subjects were assessed in the standing position, with the upper limbs extended along the body, and at a $15 \mathrm{~cm}$ mouth-microphone distance. 3 speech therapists, specialized in voice, and with over 3 years' experience of voice assessment, analyzed the auditory-perceptual parameters. The GIRBAS scale $(G=$ dysphonia global grade, $\mathrm{I}=$ instability, $\mathrm{R}$ = roughness, $\mathrm{B}$ = breathiness, $\mathrm{A}=$ asthenia, $\mathrm{S}=$ strain) was used for auditory assessment of voice quality.

For the computerized acoustic assessment of voice sounds, the Vox Metria software was used, with the same method employed for the recording of the voice samples for the auditory-perceptual analysis. The fundamental frequency (f0) and the glottal-to-noise excitation ratio (GNE) were the measures considered for this analysis [6].

For the assessment of voice handicap, the VHI questionnaire was used, according to Moerman et al [7].

\section{Statistical Analysis}

The data were analyzed through the $\chi^{2}$ test with the SPSS 15.0 software [8]. Continuous variables had their means calculated, and were aligned and analyzed through Student's t test. Comparison of ordinal variables (quality of life and voice quality scales) with nominal outcomes (type of treatment, sex, tumor site) was made through Kruskal Wallis's test. Statistical significance was set at $5 \%$.

The study met the guidelines of the Helsinki Declaration and the 196/96 Resolution of the Brazilian National Health Council [9].

\section{Results}

Table 1 shows the sociodemographic, lifestyle and occupational features of the sample.

Table 2 shows tumor characterization and therapeutic approach.

The acoustic and auditory parameters of voice quality are shown in table 3 .

Table 1 Head and neck cancer - sample characterization, Brazil, 2009.

\begin{tabular}{lll}
\hline \multicolumn{3}{c}{ SAMPLE CHARACTERIZATION } \\
\hline Variable & Frequency \\
\hline Smoking & \\
Yes & & \\
Present & 4 & $16 \%$ \\
Former & 16 & $64 \%$ \\
\hline No & 5 & $20 \%$ \\
Daily use & 15 cigarettes/day & \\
\hline
\end{tabular}

\begin{tabular}{lll}
\hline Alcohol use & & \\
Yes & 11 & $44 \%$ \\
Present & 8 & $32 \%$ \\
Former & 6 & $24 \%$ \\
\hline No & 4 doses & \\
Daily intake &
\end{tabular}

Source: Research data. 
Table 2 Tumor characterization and therapeutic approach, Brazil, 2009.

\begin{tabular}{|c|c|c|}
\hline \multicolumn{3}{|c|}{ TUMOR CHARACTERIZATION } \\
\hline Variable & \multicolumn{2}{|c|}{ Frequency } \\
\hline Squamous cell carcinoma & 19 & $76 \%$ \\
\hline Other types & 6 & $24 \%$ \\
\hline \multicolumn{3}{|l|}{ UICC Stage } \\
\hline । & 6 & 24 \\
\hline$\|$ & 8 & 32 \\
\hline III & 6 & 24 \\
\hline IV & 5 & 20 \\
\hline \multicolumn{3}{|l|}{ Tumor site } \\
\hline Mouth & 3 & $12 \%$ \\
\hline Pharynx & 7 & $28 \%$ \\
\hline Oropharynx & 3 & $12 \%$ \\
\hline Nasopharynx & 1 & $4 \%$ \\
\hline Hypopharynx & 3 & $12 \%$ \\
\hline Larynx & 15 & \\
\hline Glottis & 12 & $48 \%$ \\
\hline Supraglottic & 3 & $12 \%$ \\
\hline \multicolumn{3}{|l|}{ Therapy } \\
\hline Radiotherapy & 11 & $44 \%$ \\
\hline Radiochemotherapy & 14 & $56 \%$ \\
\hline \multicolumn{3}{|l|}{ Treatment } \\
\hline Curative & 22 & $88 \%$ \\
\hline Palliative & 3 & $12 \%$ \\
\hline \multicolumn{3}{|l|}{ Neck emptying } \\
\hline \multicolumn{3}{|l|}{ Yes } \\
\hline Unilateral & 6 & $24 \%$ \\
\hline No & 19 & $76 \%$ \\
\hline
\end{tabular}

None of our subjects reported professional voice use (singing or speech). Yet 36\% reported voice use in the working environment and $84 \%$ in daily life conversation.

During the study period, the following frequencies referred to the year of diagnosis/treatment: $8 \%$ (2000); $20 \%$ (2002); $12 \%$ (2003); 20\% (2004); $12 \%$ (2005); and $28 \%$ (2006). Our sample had no case referring to the year 2001.

$79 \%$ of the subjects complained of hoarseness preceding their diagnosis. After radiotherapy, the patients complained of: throat clearing (56\%), hoarseness (40\%), hearing impairment (40\%), and fatigue and vocal effort (8\%). No patient reported aphony. As for vocal symptoms grading, $42.9 \%$ had grade I dysphonia and $47.6 \%$ had grade II dysphonia. The most frequent resonance type was laryngeal $(56 \%)$. In spite of the large number of communication complaints, only $32 \%$ were referred to speech therapy.
Table 3 Acoustic and auditory analysis parameters, Brazil, 2009.

\begin{tabular}{lll}
\hline \multicolumn{3}{c}{ ACOUSTIC AND AUDITORY ANALYSIS PARAMETERS } \\
\hline Variable & Frequency \\
\hline Auditory analysis of voice quality & & \\
\hline Hoarse & 19 & $76 \%$ \\
Hoarse-breathing & 3 & $12 \%$ \\
Rough & 5 & $20 \%$ \\
Crepitating & 4 & $16 \%$ \\
\hline GIRBAS & & \\
Normal & 6 & $24 \%$ \\
Mild & 10 & $40 \%$ \\
Moderate & 9 & $36 \%$ \\
\hline Acoustic analysis of voice quality & & \\
\hline Fundamental frequency & & \\
Females & 184 & $221 \mathrm{~Hz}$ \\
Males & 92 & $241 \mathrm{~Hz}$ \\
\hline GNE & & \\
$<50$ & 2 & $8 \%$ \\
$51-60$ & 1 & $4 \%$ \\
$61-70$ & 3 & $12 \%$ \\
$71-80$ & 7 & $28 \%$ \\
$81-90$ & 8 & $32 \%$ \\
$91-100$ & 4 & $16 \%$ \\
\hline
\end{tabular}

GIRBAS - ( $G$ = dysphonia global grade, I = instability, $R=$ roughness, B = breathiness, $\mathrm{A}=$ asthenia, $\mathrm{S}=$ strain); $\mathrm{GNE}$ - Glottal-to-noise excitation ratio. Source: Research data.

Table 3 shows the vocal characterization of the 25 subjects who underwent organ preservation protocols.

On bivariate analysis, there was no association between acoustic analysis and sex $(\mathrm{p}=0.385)$, or between acoustic analysis and GIRBAS scale $(\mathrm{p}=0.391)$. GIRBAS worsened according to anatomical location ( $\mathrm{p}$ $=0.002)$ and year of treatment $(\mathrm{p}=0.017)$, and speech therapy increased the likelihood of GIRBAS $=1(\mathrm{p}=$ 0.048). It is noteworthy that implementation of speech therapy was influenced by sex $(\mathrm{p}=0.057)$.

The main results of VHI indicated that the quality of life showed mild physical, functional and emotional handicaps. As for difficulty to be understood, $80 \%$ reported moderate difficulty, and $12 \%$ always or almost always had to repeat what they had just said, in order to be understood. Notwithstanding, $64 \%$ considered themselves talkative or extremely talkative. $40 \%$ considered their voices to have a rough pitch, $24 \%$ found their voices to be unpredictably clear, and $12 \%$ always or almost always had to make an effort to speak. In $20 \%$ the voice disappeared halfway through conversation, $8 \%$ felt embarrassed when speaking, and $8 \%$ always or almost always felt incompetent when speaking. 


\section{Discussion}

According to epidemiological data, age is one of the main risk factors for cancer development, a finding that points to an increase in cancer incidence with gains in life expectancy. $76 \%$ of our patients were males, with mean age of 64 years. Besides genetic factors, smoking and alcohol use increase the chances of head and neck cancer, with squamous cell carcinoma as the predominant histological type. In our sample, 64\% were former smokers and $32 \%$ former alcohol users, with $44 \%$ present alcohol users. Mean alcohol and tobacco use time was 40 years, with 4 doses and 15 cigarettes a day, on average.

Recent studies have shown good results with organ preservation approaches that use radiochemotherapy. Although survival time is not affected, laryngeal function is not always preserved, as state Hirsch et al [10]. In our study, radiochemotherapy was used in $56 \%$ of the subjects, followed by radiotherapy alone in $44 \%$. A 7000 Gy dose was applied to $64 \%$, with a 5000 Gy fossa dose in $81 \%$. Treatment was curative in $88 \%$.

We chose to use a combination of objective and subjective measurements, according to Leeper et al [11]. Those authors concluded that, although subjective measurements of voice quality are important, objective measurements are necessary to assess subtle voice changes with time.

According to Behrman, Abramson and Myssiorek [12], $80 \%$ of prospectively studied patients had changes in their voice quality 1 year after radiotherapy. $40 \%$ of our patients still complained of hoarseness, and $56 \%$ of throat clearing, even 3 years after treatment.

Carrara-de Angelis et al. [13] concluded that of 15 patients who had received radiochemotherapy for laryngeal cancer, $33 \%$ had adequate voice quality or mild dysphonia, $40 \%$ moderate dysphonia, and $27 \%$ severe dysphonia. In a study of patients treated for glottic tumor, Caminero et al. [14] reported that $11 \%$ had normal voices, $44 \%$ had mild dysphonia, $28 \%$ had moderate dysphonia, and $17 \%$ had severe dysphonia. Those authors also reported VHI results that were close to normal. Our results were slightly better, with the following characteristic voices: hoarse $(76 \%)$, hoarse-breathing $(12 \%)$, rough $(20 \%)$, and crepitating (16\%). On the GIRBAS scale, $24 \%$ had normal voice, $40 \%$ mild dysphonia, and $36 \%$ moderate dysphonia.

Our study showed that although most subjects had mild physical, functional and emotional handicaps, several aspects of communication were impaired.

The communication problems identified in our study were: moderate difficulty to be understood, need to repeat what had been said, poor voice quality, need to make an effort to speak, and difficulty to socialize (embarrassment to speak and feeling of incompetence when speaking).

Voice quality was associated with speech rehabilitation in our study. The same finding was reported by Van Gogh et al. [15], who concluded that speech therapy was effective for patients complaining of voice impairment after treatment for early glottic carcinoma. Improvement was significant with VHI analysis, and was also confirmed through the objective voice parameters assessed.

\section{Conclusions}

Our study results cannot be generalized, because of the small number of patients meeting the inclusion criteria and a possible survival bias that may have overestimated the perception of voice and quality of life. Yet our results suggest an important reflection on radiotherapy and its sequelae. Communication and quality of life after treatment for head and neck cancer are an important issue, once longer survival should assume satisfactory community interaction.

Our findings revealed that even after years of cancer treatment completion, there remain voice symptoms able to interfere with the quality of life. Chemio-radiation organ preservation protocols in the patients studied may leave the organ but with reduced function. Therefore, the integration of the speech therapist in the head and neck cancer treatment teams should bring techniques that will ease patient communication.

\section{Acknowledgements}

We are grateful to the directors of the Instituto Oncológico of Juiz de Fora: Dr. Narciso Francisco Pazzinato, Dr. Tereza Cristina Esteve and Dr. Olamir Rossini Júnior. Thanks are also due to the radiotherapist Luciana Vignoli and the colleagues Aline Mendes Ferrugini, Dr. Elisabete Carrara-de Angelis and Dr. Sandra Pela. Finally, we wish to thank Dr. Darcília Maria Nagen da Costa, teaching coordinator of the Post-Graduate Program in Brazilian Health, of the Juiz de Fora Federal University.

\section{Author details}

'Instituto Oncológico of Juiz de Fora; Voice specialist; Brazilian Health Master Program of the Federal University of Juiz de Fora, Minas Gerais, Brazil.

${ }^{2}$ Hospital Monte Sinai; Brazilian Health Master Program of the Federal University of Juiz de Fora, Minas Gerais, Brazil. ${ }^{3}$ XXII Programa De Bolsas De Iniciação Científica Bic/Ufjf, Federal University of Juiz de Fora, Minas Gerais, Brazil. ${ }^{4}$ Federal University of Juiz de Fora, Minas Gerais, Brazil.

\section{Authors' contributions}

RJDSC and ICGL have made contributions to conception and design of the study, acquisition of data and helped to draft and revision the manuscript. CTVM and MGC have made contributions to acquisition of data and helped to draft and revision the manuscript. All authors read and approved the final manuscript.

\section{Competing interests}

The authors declare that they have no competing interests.

Received: 25 March 2011 Accepted: 19 April 2011

Published: 19 April 2011 


\section{References}

1. Eksteen EC, Rieger J, Nesbitt M, Seikalv H: Comparison of voice characteristics following three different methods of treatment for laryngeal cancer. J Otolaryngol 2003, 32(Suppl 4):250-3.

2. Costa Bandeira AK, Azevedo EH, Vartanian JG, Nishimoto IN, Kowalski LP, Carrara-de Angelis E: Quality of life related to swallowing after tongue cancer treatment. Dysphagia 2008, 23(Suppl 2):183-192.

3. Jacobson BH, Johson A, Grywalski C, Silbergleit A, Jacobson G, Benninger MS: The voice Handicap Index (VHI): Development and validation. Am J Speech Lang Pathol 1997, 6:66-70.

4. Brasil, Ministério da Saúde. Datasus. Brasília: Ministério da Saúde. [http:// www.datasus.gov.br]

5. Rehder MI, Behlau M: Perceptual, auditory and acoustic vocal analysis of speech and singing in choir conductors. Pro Fono 2008, 20(Suppl3):195-200.

6. Sampaio M, Oliveira G, Behlau M: Investigação de efeitos imediatos de dois exercícios de trato vocal semi-ocluído. Pró-Fono Revista de Atualização Científica 2008, 20(Suppl 4):261-6.

7. Moerman M, Martens JP, Dejonckere P: Application of the Voice Handicap Index in $\mathbf{4 5}$ patients with substitution voicing after total laryngectomy. Eur Arch Otorhinolaryngol 2004, 261(Suppl 8):423-8.

8. SPSS INCORPORATION: SPSS for Windows. Statistical Package for Social Sciences. Release 15.0 Chicago: SPSS Inc; 2006.

9. Conselho Nacional de Saúde. Resolução n. 196. (10/11/2010). [http:// conselho.saude.gov.br/resolucoes/1996/Reso196.doc].

10. Hirsch SM, Caldarelli DD, Hutchinson JC, et al: Concomitant chemotherapy and split-course radiation for cure and preservation of speech and swallowing in head and neck cancer. Laryngoscope 1991, 101(6 Pt 1):583-6.

11. Leeper HA, Parsa V, Jamieson DG, Heeneman H: Acoustical Aspects of Vocal Function Following Radiotherapy for Early T1a Laryngeal Cancer. Journal of Voice 2002, 16(Suppl 2):289-302.

12. Behrman A, Abramson AL, Myssiorek DAA: Comparison of radiation of radiation-induced and prebylaryngeal dysphonia. Otolaryngology Head neck surgery 2001, 125:193-200.

13. Carrara-de Angelis E, Feher O, Barros AP, Nishimoto IN, Kowalski LP: Voice and swallowing in patients enrolled in a larynx preservation trial. Arch Otolaryngol Head Neck Surg 2003, 129:733-738.

14. Caminero CMJ, Señaris GB, López LA, Núñez BF, Alonso PR, Suárez NC Voice quality assessment after laryngeal cancer radiotherapeutic treatment at initial stages. Clin Trans/ Oncol 2006, 8(Suppl 4):284-9.

15. Van Goch CD, et al: The efficacy of voice therapy in patients after treatment for early glottic carcinoma. Cancer 2006, 106(Suppl 1):95-105.

doi:10.1186/1758-3284-3-19

Cite this article as: Campos et al:: Voice analysis after cancer treatment with organ preservation. Head \& Neck Oncology 2011 3:19.

\section{Submit your next manuscript to BioMed Central and take full advantage of:}

- Convenient online submission

- Thorough peer review

- No space constraints or color figure charges

- Immediate publication on acceptance

- Inclusion in PubMed, CAS, Scopus and Google Scholar

- Research which is freely available for redistribution

Submit your manuscript at www.biomedcentral.com/submit
C Biomed Central 